\title{
Challenges encountered in the implementation of a diet and exercise intervention for low-income Hispanic older adults with diabetes
}

\author{
Joan A. Vaccaro ${ }^{1 *}$, Trudy Gaillard ${ }^{2}$ Stephanie Caceres ${ }^{3}$, Monica Hollifield ${ }^{4}$, and \\ Fatma G. Huffman ${ }^{5}$ \\ ${ }^{1}$ Department of Dietetics and Nutrition, Florida International University, Miami, FL, USA; jvaccaro@fiu.edu \\ ${ }^{2}$ College of Nursing, Florida International University, Miami, FL, USA; tgaillar@fiu.edu \\ ${ }^{3}$ Department of Physical Therapy; Florida International University, Miami, FL, USA; scace001@fiu.edu \\ ${ }^{4}$ Department of Dietetics and Nutrition, Florida International University, Miami, FL, USA; mholl058@fiu.edu \\ ${ }^{5}$ Department of Dietetics and Nutrition, Florida International University, Miami, FL, USA; huffmanf@fiu.edu \\ * Correspondence: jvaccaro@fiu.edu Tel.: 305-348-0368 (USA)
}

\begin{abstract}
The purpose of this study was to present the challenges faced when implementing a diet and exercise intervention for low-income older Hispanics with type 2 diabetes with an observational study of recruitment, attendance, and characteristics of Hispanic adults with type 2 diabetes in a community congregate meal site pre and post administration of a diet and exercise intervention. This report evaluates retentions and diabetes self-management beliefs Hispanic adults $\geq 60$ years with type 2 diabetes ( $n=17)$ at baseline, and completion of the six-month intervention in terms of the Health Belief Model. There was limited interest in controlling diabetes with diet and exercise. Major barriers included lack of perceived vulnerability to diabetes complications and a belief that medication alone is sufficient to stabilize blood glucose. Environmental barriers included lack of transportation, access to exercise groups, access grocery stores, and limited ability to pay for healthy foods. A lesson learned from this intervention was that the diet and exercise intervention given was insufficient as a cue to action for this population interventions to engage low-income, older Hispanics with diabetes in diet and exercise need to consider strategies to overcome barriers such as health beliefs, transportation issues, lack of access to nutritious food and group exercise classes.
\end{abstract}

Keywords: low-income Hispanics; type 2 diabetes; diet and exercise intervention; older adults; Health Belief Model

\section{Introduction}

Type 2 diabetes is a major health concern in the U.S. affecting $9.3 \%$ of the general population, $26 \%$ of adults 65 years and older and nearly twice as many Hispanics have type 2 diabetes compared to non- Hispanic Whites [1]. According to the American Diabetes Association, the estimated cost of diabetes in the U.S. was $\$ 327$ billion in 2017 [2]. Many older adults with type 2 diabetes have mobility impairments and experience falls [3]. The direct medical costs of fall-related injuries in the U.S. was $\$ 31$ billion in 2015; it is estimated that it will reach $\$ 68$ billion in 2020 [4,5].

The recommended method to reduce diabetes-related complications and costs is to provide education on diabetes management and maintain glycemic control [6,7]. Yet, the standard of care provides only one diabetes self-management session per year. Additional sessions are recommended 
only when medical complications occur [8]. Diabetes education programs are less likely to be offered and more likely to be discontinued in economically disadvantaged communities due to lack of referrals and reimbursement [8]. In addition, socioeconomic deprivation is associated with decreased physical activity and increased sedentary behavior in older adults [9].

Potentially preventable hospital admissions in Florida have increased 21\% from 2014-2015 to 2016-2017 and diabetes ranked eight among the conditions leading to admission at 5.5\% for 20162017 [10]. Hispanics have over twice the percent of undiagnosed cases (4.5\% versus $2.0 \%$ ) [11]. Hispanics also experience higher rates of diabetes complications than non-Hispanic Whites and 1.4 times the death rate from diabetes compared to non-Hispanic Whites [11, 12].

Interactive diet and exercise interventions in older, low-income Hispanics with type 2 diabetes have not been reported. Hu, Wallace, McCoy and Amirehsaniv [13] conducted a familybased diabetes intervention for Hispanic adults, however the average age was 41 years and their lesson content and approach differed greatly from this current study. Health literacy and health beliefs are barriers for diet and exercise interventions in Hispanics [14]. The purpose of the current study was to test a culturally appropriate diet and exercise intervention for Hispanics 60 years old or older with type 2 diabetes (T2DM). This report presents the challenges encountered in implementing a diet and exercise intervention in terms of the relationships among participants' characteristics, retention, participation, and diabetes self-management beliefs.

\section{Materials and Methods}

2.1.1 Study design: This report evaluates the 'diet and exercise arm' from recruitment, baseline, and completion of the intervention at six-months of a larger study. The study was approved by the institutional review board and all participants read and signed an informed consent form in Spanish.

2.1.2 Setting: A senior center and congregate meal site serving low-income, primarily Hispanic adults ages 60 and older in the in the southeastern United States.

2.1.3 Participants: The participants were older Hispanics with T2DM. Inclusion criteria: 1) Have T2DM confirmed by hemoglobin A1C (A1C) and blood glucose testing; 2 ) Age $\geq 60$ years; 3 ) Score $\geq 3$ on the Mini Cognitive Screener [15] indicating sufficient cognitive ability to comprehend diet and exercise lessons; 4) Score $\geq 17$ on the Mini Nutrition Screener (MNS) [16] indicating that medical nutrition intervention was not needed. Malnourished seniors were referred to the site's social worker to be referred for medical treatment. Exclusion criteria: not willing or not able to exercise in standing due to medical issues or physical limitations (e.g. wheelchair-bound); malnutrition; on dialysis; with liver disease, cancer, HIV/AIDS, or other physical/psychological condition preventing participation. In addition, participants who were found to have $\mathrm{A} 1 \mathrm{C}>8.5$ during the baseline assessment were referred to medical care for safety reasons.

2.2 Recruitment procedures and ethics: This study was approved by Institutional Review Board of Florida International University. This study was performed in line with the principles of the Declaration of Helsinki. The manuscript is based on a study that was approved by the Institutional Review Board (IRB) through Florida International University's IRB Protocol: IRB-190037AM04 and filed as grant number NCT04132739 under clinical trials: https://clinicaltrials.gov/ct2/show/NCT04132739?term=NCT04132739\&draw=2\&rank=1. Informed consent forms were signed by all participants. Flyers were posted at the site and team members made 
announcements about the study during periods of high attendance (e.g. prior to lunch). Potential participants provided their phone numbers for further explanations and scheduling.

2.5 Conceptual framework: The conceptual framework for this study was based on the Health Belief model adapted from Green and Murphy [17] (Figure 1). Diabetes education, diet and exercise fit into "cues to action". The intervention goal was to alter the participants' perceptions and increase in the likelihood of improving diet and increasing exercise. The anticipated Mechanism of Action of the diet and exercise interventions include improved diet quality and lipid profile [18], increased protein, vitamin $\mathrm{D}$ and calcium intake, increased antioxidants from fruits and vegetables, reduced hemoglobin A1C, improve physiological function, increased energy for physical activity, increased muscle mass, and reduce falls and hospitalizations.

\section{Individual Perceptions Modifying Factors Likelihood of action}

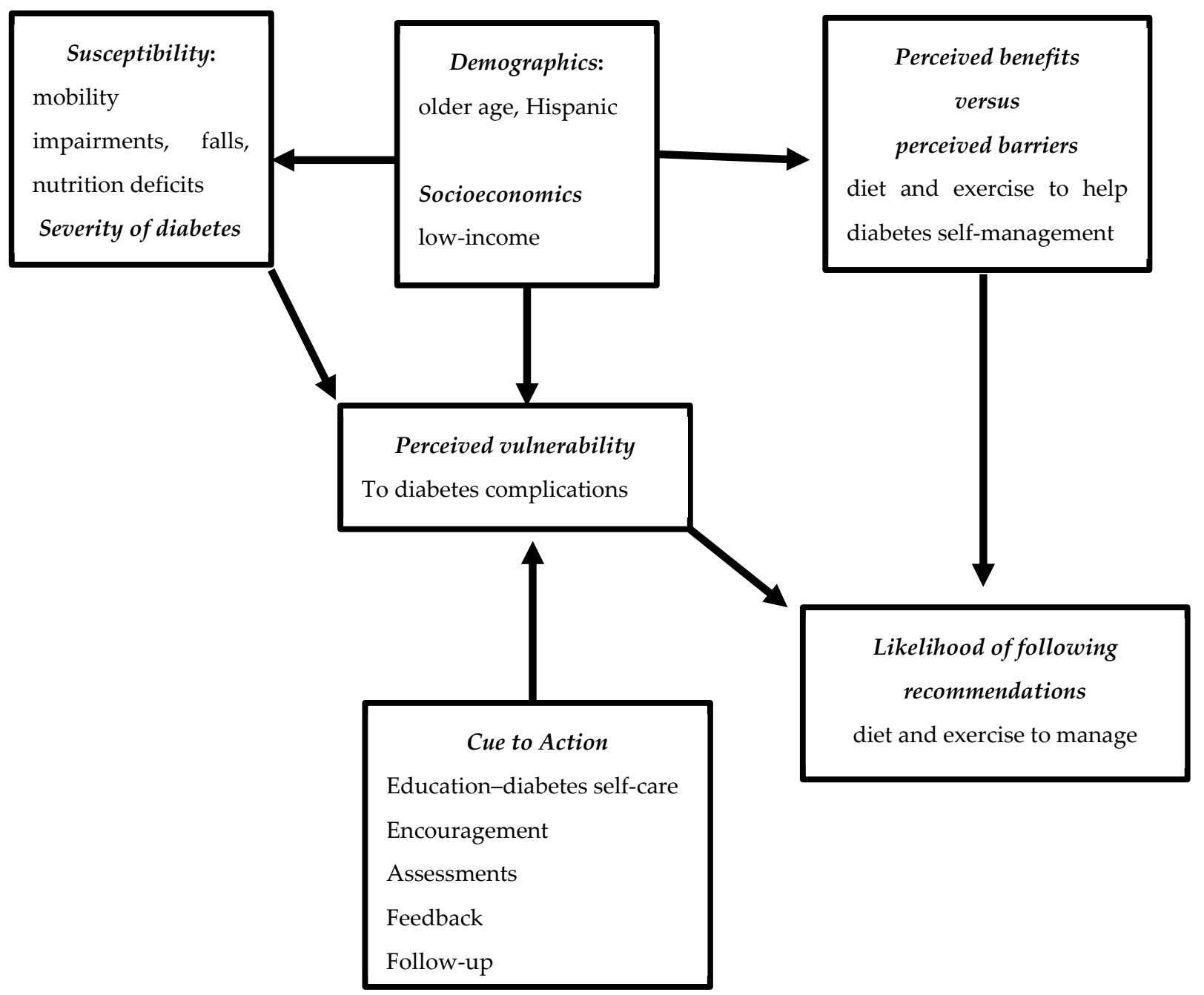

Figure 1. Health Belief Model adapted to this study from Green and Murphy [17].

2.3 Intervention Materials: Interventions were conducted in Spanish by dietetics and nutrition and by physical therapy students twice a week with 30 minutes of diet lessons followed by 30 minutes of exercise lessons. A 10-minute break was given in-between the diet and exercise classes with water and fruit provided. 
2.3.1 Diet lessons: Diet lessons were based on materials from Dietary Guidelines for Older Americans [19], MyPlate for Diabetes [20] and Diabetes Educator's food and nutrition recommendations [21]. Various methods of instruction were applied during the six months. First, power point presentations were used with discussions for the first three months. The final intervention delivered from three to six months was done with individual assessment in a small group setting of 24-hour recalls and worksheets to teach carbohydrate counting and collaborative modifications for the participants' meal options. Discussion of hyperglycemia and scheduling of meals and exercise were integrated into the format as per the needs of the participants. The food quality change was measured using a Food Frequency Questionnaire and validated in Hispanic populations. The goals were to increase the participants' self-efficacy (belief and self-confidence) that they could follow the diabetes diet.

2.3.2 Exercise lessons: Exercise lessons were tailored for needs and capabilities of the participants and involved short conversations ( $\sim 5 \mathrm{~min}$ ) about physical function, falls risks and prevention, exercise effects on diabetes and other exercise-related topics, followed by 30-minute exercise sessions. The intervention was developed based on the Otago Exercise Program, which is effective in reducing falls in community-dwelling older adults [22-24]. It was piloted and well accepted by older Caribbeans [25], but it had not been tested in older Hispanics, nor in people with T2DM. The exercises involved lower and upper limb strengthening, balance training and a walking plan. Based on the baseline assessment, the participants received individualized exercise parameters and instructions on which resistance bands to use, walking time (up to 30 minutes 2x/week) and safety instructions. Exercises were demonstrated by Physical Therapy students and bilingual students assisted in helping and guarding participants to prevent improper form, injuries, or falls. Exercises included stretch and warm-up, balance, aerobics, strength, and cool down.

Aside from the 30 minutes of exercise twice a week on site, the participants were encouraged to do the exercises by themselves on days the group sessions were not offered and provided with exercise $\log$ sheets.

2.4 Data Analysis: Attendance was calculated as percent of participation for the total number of available sessions (Table 1). Demographics and biomarkers were presented as means and standard deviations for continuous variables such as age, years with diabetes, hemoglobin A1c (A1C), and blood pressure. Demographics for categorical variables (sex, education, marital status, and method of controlling diabetes were calculated and presented as frequency and percent (Table 2). The scale for diabetes self-management was the total of Likert scores coded for the higher numbers to reflect better diabetes self-management. In addition, a sub-scale for diabetes self-efficacy was created. Pearson's correlations were used to show the association of perceived diabetes self-management and diabetes self-efficacy with attendance (Table 3).

\section{Results}

\subsection{Recruitment results:}

There were approximately 40 members of the senior center that were known to have diabetes. Out of the potential participants, 23 showed an initial interest in the study; six did not pass the screening 
(one failed the cognitive test and five were not willing to come in for the assessment) leaving $\mathrm{N}=17$ participants.

\subsection{Program participation:}

During the recruitment phase, those who were interested were provided additional information regarding the study. Approximately half of eligible members stated that they did not believe they needed diet and exercise to manage their diabetes because they could regulate their blood glucose using medication. Others expressed enthusiasm for the educational sessions that would be offered or the A1C screening at each evaluation session from baseline to 3, 6, and 9 months. Most of the people who approached the recruitment team mentioned how they were pre-diabetic and were very interested in learning, but unfortunately fell into our exclusion criteria and could not participate.

During the intervention, the average class size was four participants. Individual attention for diet and exercise was given. The diet recalls and individual counseling resulted in only one participant modifying their diet. The exercise logs showed there was little change in their exercise routine from the beginning to the end of the program. Participants' attendance is shown in Table 1.

Table 1. Attendance for diet and exercise site lessons: 3-months and 6 months (completion)

\begin{tabular}{llll}
\hline Participant & \multicolumn{2}{l}{ Number of days } & Number of \\
& $\begin{array}{l}\text { Attended } \\
\text { months (\%) }\end{array}$ & $\begin{array}{l}\text { Attended } \\
\text { days }\end{array}$ \\
& & months (\%) \\
\hline 1 & $26(96)$ & $42(95)$ \\
2 & $22(81)$ & $26(59)$ \\
3 & $12(44)$ & $17(39$ \\
4 & $4(15)$ & $4(9)$ \\
5 & $15(56)$ & $15(34)$ \\
6 & 0 & 0 \\
7 & $3(11)$ & $3(7)$ \\
8 & $9(33)$ & $14(32)$ \\
9 & 0 & 0 \\
10 & 0 & 0 \\
11 & $4(15)$ & 4 \\
12 & $1(4)$ & $1(2)$ \\
13 & 0 & 0 \\
14 & $22(81)$ & $32(73)$ \\
15 & $7(26)$ & $15(34)$ \\
16 & $6(22)$ & $6(14)$ \\
17 & $3(11)$ & $3(7)$ \\
\hline
\end{tabular}

*site closures and holidays accounted for less sessions than anticipated.

There were four no shows. For the first three months, three participants had greater than $80 \%$ attendance. The overall attendance for the six-month intervention shows only two participants with $70 \%$ or greater attendance. Two participants fell during the study period : one male fell as a result of vertigo, and a female was without her walker and fell due to loss of balance outside her home. 
The participants' demographics and biomarkers are shown in Table 2. The majority of the participants were between 72 and 84 years. There were wide variations in years diagnosed with diabetes, glycemic control, and blood pressure. Three-quarters of the participants were women. There was a bimodal distribution for education with the majority either having a low education level or some college, full college, or technical school. The majority of the participants were widows/widowers. Medications were reported as the means for controlling diabetes for $58 \%$ of the participants. Four participants who stated that they used diet and/or exercise to control their diabetes never attended classes. Waist circumference $>102 \mathrm{~cm}$ for males and $>88 \mathrm{~cm}$ for females characterize central obesity [26]. The International Diabetes Federation (IDF) [27] defines central obesity and risk for metabolic syndrome at smaller waist measures (males: $>94 \mathrm{~cm}$; females: $>80 \mathrm{~cm}$ ). Ethnicities from Central and South America are considered to have central obesity if their measures are $>90 \mathrm{~cm}$ for males and $>80 \mathrm{~cm}$ for females [27]. Among the participants ( $\mathrm{n}=4$, males; $\mathrm{n}=13$ females) $50 \%$ to $75 \%$ of males and $69 \%$ to $92 \%$ of females had central obesity depending on the cutoffs used.

Table 2. Demographics and biomarkers of the participants

\begin{tabular}{|c|c|c|c|c|c|}
\hline Continuous variables & $N$ & Minimum & Maximum & Mean & $S D$ \\
\hline Age (years) & 17 & 68 & 89 & 78.4 & 6.7 \\
\hline Hemoglobin A1C & 13 & 5.4 & 9.6 & 7.0 & 1.0 \\
\hline Years diagnosed with diabetes & 17 & 2 & 41 & 15 & 10 \\
\hline Systolic blood pressure & 15 & 131 & 182 & 147 & 16 \\
\hline Diastolic blood pressure & 15 & 68 & 90 & 78 & 6.8 \\
\hline Categorical variables & Frequency & Percent & & & \\
\hline Males & 4 & 23.5 & & & \\
\hline Females & 13 & 76.5 & & & \\
\hline \multicolumn{6}{|l|}{ Education } \\
\hline $8^{\text {th }}$ grade or less & 7 & 41.2 & & & \\
\hline High school diploma/GED & 3 & 17.6 & & & \\
\hline Some college, college, technical & 7 & 41.2 & & & \\
\hline \multicolumn{6}{|l|}{ Marital status } \\
\hline Currently married & 1 & 5.9 & & & \\
\hline Widowed & 9 & 52.9 & & & \\
\hline Separated or divorced & 5 & 29.4 & & & \\
\hline Never married & 2 & 11.9 & & & \\
\hline \multicolumn{6}{|l|}{ How do you control your diabetes? } \\
\hline Insulin & 3 & 17.6 & & & \\
\hline Hypoglycemic medications & 10 & 58.8 & & & \\
\hline Diet or exercise & 4 & 23.5 & & & \\
\hline
\end{tabular}

Abbreviation: GED = General Education Development or General Education Diploma

\subsection{Participants' Feedback}

Participants' feedback during lessons revealed several barriers to diabetes management. Barriers to adequate diet included economics, ability and desire to prepare meals, food preferences, health 
beliefs - in particular, that medication can take the place of healthy eating to regulate blood glucose. Barriers to exercise included mobility issues, vertigo, pain, and fear of falling.

Correlation of diabetes self-management (DSM) with attendance is shown in Table 3. There were no relationships among attendance and the participants' perception of their diabetes self-management beliefs, motivation, and practices. The association of diabetes education on perceived vulnerability to diabetes complications could not be assessed due to low attendance and retention.

Table 3. Perceived diabetes self-management and intervention attendance

\begin{tabular}{|c|c|c|}
\hline Diabetes self-management scores & Percent 3-month attendance & Percent \\
\hline \multirow[t]{2}{*}{ Full score, DSM } & $\mathrm{r}=0.22$ & $\mathrm{r}=0.32$ \\
\hline & $p=.407$ & $p=.209$ \\
\hline DSM subscale: DSM is not & $\mathrm{r}=0.16$ & $\mathrm{r}=0.29$ \\
\hline difficult, and I am confidence I can & $p=.548$ & $p=.257$ \\
\hline \multicolumn{3}{|l|}{ manage my diabetes } \\
\hline
\end{tabular}

Health beliefs for diabetes self-management are presented in Table 4. A significant percent of the population reported that they would have to change too many habits to follow their diet, become more active, and to take their medications.

Table 4 . Health beliefs for diabetes self-management

\begin{tabular}{lll} 
Health belief diabetes care & Agree N(\%) & Disagree N(\%) \\
\hline $\begin{array}{l}\text { I would have to change too many } \\
\text { habits to follow my diabetes diet }\end{array}$ & $10(58.8)$ & $11(64.7)$ \\
$\begin{array}{l}\text { I would have to change too many } \\
\text { habits to become more active }\end{array}$ & $6(35.3)$ & $13(76.5)$ \\
$\begin{array}{l}\text { I would have to change too many } \\
\text { habits to take meds }\end{array}$ & $4(23.5)$ & \\
\hline
\end{tabular}




\section{Discussion}

Application of the Health Belief Model to this study suggests that the participants may not perceive the severity of their condition and their susceptibility to declining health and loss of physical function. The belief that medication alone was enough to successfully manage their diabetes was widespread among the eligible members and limited their interest and willingness to join and complete the study. Approximately half of the eligible members explained that they can manage their diabetes with medication, and they did not need to change their diet or increase exercise. Attrition was $88 \%$ as compared to $24 \%$ attrition reported in an exercise intervention for a cohort of older adults (primarily White non-Hispanic) [28]. Attrition may be attributed to diabetes health beliefs. Since the majority of participants stated that they would have to change too many habits to follow the diabetes diet $(58.8 \%)$ and one-third indicated that they would have to change too many habits to become more active (35.3\%). Attrition has been related to low-self efficacy for several intervention studies in older adults $[28,29]$.

Several barriers to achieving diet: stress, lack of willpower, and the food home environment and exercise: time, fatigue, and lack of motivation in a middle-aged group of low-income Hispanics at risk for diabetes [30]. Family and intergenerational households were barriers to preparing healthy food where focus groups stated changing the way meals are prepared or how grocery shopping is done would not be tolerated by other members of the household [31]. The dietary barriers expressed by participants in the current study were that healthy foods such as fish, lean meats, and vegetables were too expensive, dislike of or unfamiliarity with preparing many vegetables, habit, and lack of motivation to prepare healthy meals. The dietary recalls of the participants in the current study showed limited fruit and vegetable consumption. Although frozen vegetables are cheaper than fresh, one participant only enjoys fresh spinach and can only buy it when it is on sale. Due to their advanced age and financial status, several participants ate very little outside of the meal received at the congregate site. Meals eaten away from the center usually involved dairy (yogurt was very common) and some form of crackers or bread, leaving little room for, or desire to include, fruits and vegetables in the diet. Eating fruits and vegetables to help diabetes was considered a barrier due to economic constraints for low-income Hispanics with diabetes [14].

In the current study, pain, fear of falling, vertigo, and mobility issues were expressed by the participants as reasons for avoiding exercise. Possible reasons for mobility issues in older adults with T2DM were reported as follows: diabetes-related polypharmacy, musculoskeletal pain, poorer selfperceived health, lower levels of physical activity and muscle strength, impaired gait or balance, and cognitive impairment [32]. The aging process positively trends towards lower muscle mass, higher visceral fat, and osteoporosis, which commonly affects individuals of advanced years and can lead to poor outcomes after falls [33]. Although lack of motivation was not expressed for participants in the current study, most participants failed to provide exercise logs and/or showed little change in current exercise throughout the intervention. Barriers for participants in the current study may be a combination of advanced age and multiple medical issues.

Furthermore, effective self-management of diabetes behaviors has been shown to directly link to knowledge and employment status [34], providing another possible barrier that could relate to socioeconomic deprivation and acquisition of healthy affordable foods. Health beliefs are another barrier to diabetes care for this population of older Hispanics. Persons of low education and income tend to rely on medication to stabilize their condition and negate the role of diet and exercise as 
demonstrated in Danish adults (40-60 years old) diagnosed at risk for heart disease [35]. Medication was considered providing tangible results as opposed to diet and exercise according to low-income urban Hispanics and Blacks with diabetes [36]. Aside from having limited access to healthy foods, they expected an exact diet prescription from their physician [33]. Testerman and Chase [37] reported similar barriers for attendance of diabetes self-management classes for a younger group of low-income Hispanics as found in the current study: lack of interest, transportation problems, and lack of knowledge of the effect of diabetes on health.

The exercise sessions were adapted to the level of the participants. Most of the strength and balance exercises needed supervision for those participants of limited mobility. Participants explained that they did not have the transportation to go to the free exercise classes available to seniors such as Silver-sneakers. Caballero [38] suggested that fears concerning diabetes treatment are more prevalent in Hispanics of low socioeconomic income in a review of health beliefs of Hispanics with T2D. Caballero [38] indicated that low-income Hispanics with a common health belief that their disease is beyond their control were less likely to exercise and perceive themselves as overweight.

This study has several limitations. The participant's stage of change for motivation and confidence to improve their diet and activity level was not measured. Participants who dropped the study were not available to discuss their reasons for not continuing. The barrier of access to healthy food was not addressed in the initial diet lessons. An initial meeting before the intervention inquiring as to what the participants wanted to learn could have been one approach to increase cues to action and minimize perceived barriers. Participants were asked at the second lesson what they wanted from the diet intervention and their responses were 'what should we eat?' and where can we buy healthy food on a budget?' We developed and integrated these lessons (process evaluation) into the ongoing lessons instead of addressing them immediately. The initial lessons were presentations with questions and answers rather than dynamic interactive discussions on dietary recall and suggested modifications. Whittemore et al. [39] reported that lack of access to healthy foods was a major barrier for Mexican with type 2 diabetes. The strength of this study was initiating diet and exercise education and presenting the challenges presented for a hard-to-reach population. In fact, there was only one other study similar to this current study highlighting the need for refinements in the delivery and design of interventions for low-income, older Hispanics with type 2 diabetes.

\section{Conclusions}

The diet and exercise intervention given was insufficient as a cue to action for this population. Methods to engage low-income, older Hispanics with T2DM in diet and exercise interventions need to consider strategies to overcome barriers for engagement such as health beliefs, transportation, and access. Pre-intervention engagement to discuss barriers is recommended. Another approach would be to have an open presentation discussion the long-term consequences of diet and exercise on glucose regulation and diabetes outcomes. Since physicians prescribe medication, having endocrinologists address this community in conjunction with diabetes educators may dispel these beliefs. 
Author Contributions: Conceptualization, J.A.V, T.G., S.C., M.H., and F.G.H.; methodology, J.A.V, S.C. and M.H.; software, J.A.V.; validation, T.G. and F.G.H formal analysis, J.A.V.; investigation and data curation, J.A.V., T.G., S.C., and M.H.; writing-original draft preparation, J.A.V.; writingreview and editing, T.G. and F.G.H; supervision, J.A.V, T.G., and F.G.H. All authors have read and agreed to the published version of the manuscript.

Funding: This study was supported by Wertheim Innovation Faculty Grant from the FIU Nicole Wertheim College of Nursing and Health Sciences

Acknowledgments: The authors thank Edgar R. Vieira, the Primary Investigator for project administration and allowing the co-investigators and research assistants to report these finding. Special thanks to Jennifer Garcia, an undergraduate nursing student, (Honor's College) for coordinating the materials and staff as well as collection of vitals. Jennifer also presented several classes on hypoglycemia and the timing of meals. Appreciation for all the students from the Physical Therapy Department who participating in data collection and carrying the exercise intervention. Students from the Dietetics and Nutrition Department who helped with data collection, diet lesson structure and participants' feedback. Gratitude to the many students from the Honor's College who volunteered and helped with data collection and the interventions.

Conflicts of Interest: The authors declare no conflict of interest. 


\section{References}

1. [1] Centers for Disease Control and Prevention. National diabetes statistical report, 2020: estimates of diabetes and its burden in the United States. Atlanta, GA. Center for Disease Control and Prevention, US Department of Health and Human Services, 2020. https://www.cdc.gov/diabetes/pdfs/data/statistics/nationaldiabetes-statistics-report.pdf

Accessed March 3, 2020.

2. [2] American Diabetes Association. Economic Costs of Diabetes in the U.S. in 2017. Diabetes Care 2018;41(5):917-28.

3. [3] Vieira ER, Mendy A, Prado CM, Gasana J, Albatineh AN. Falls, physical limitations, confusion and memory problems in people with type II diabetes, undiagnosed diabetes and prediabetes, and the influence of vitamins A, D and E. J Diabet Complications. 2015;29(8):1159-64.

4. [4] Florence CS, Bergen G, Atherly A, Burns E, Stevens J, Drake C. Medical Costs of Fatal and Nonfatal Falls in Older Adults. J Am Geriatr Soc. 2018;66:693-698. doi:10.1111/jgs.15304

5. [5] Englander F, Hodson TJ, Terregrossa RA. Economic dimensions of slip and fall injuries. J Forensic Sci. 1996;41(5):733-746.

6. [6] American Diabetes Association. 3. Foundations of Care and Comprehensive Medical Evaluation. Diabetes Care 2016;39 Suppl 1:S23-35.

7. [7] American Diabetes Association. 4. Lifestyle Management. Diabetes Care. 2018;40:(Suppl 1):S38-S50.

8. [8] Powers MA, Bardsley J, Cypress M, et al. Diabetes self-management education and support in type 2 diabetes: a joint position statement of the American Diabetes Association, the American Association of Diabetes Educators, and the Academy of Nutrition and Dietetics. Diabetes Educ. 2017;43(1):40-53.

9. [9] Xiao Q, Keadle SK, Berrigan D, Matthews CE. A prospective investigation of neighborhood socioeconomic deprivation and physical activity and sedentary behavior in older adults. Prev Med. 2018;111:14-20.

10. [10] Scott R, Senior JM. Analyzing potentially preventable healthcare events of Florida Medicaid enrollees 2015-2016 and 2017-2018: quarterly statewide managed care report. Tallahassee, FL. Agency for Health Care Administration. https://ahca.myflorida.com/Medicaid/Finance/data analytics/BI/docs/Quarterly SMMC Report PPE Wi nter 2018.pdf. Accessed March 3, 2020.

11. [11] Center for Disease Control and Prevention (CDC) National Diabetes Fact Sheets, 2017. Atlanta, GA. Center for Disease Control and Prevention, US Department of Health and Human Services. https://www.cdc.gov/diabetes/pdfs/data/statistics/national-diabetes-statistics-report.pdf. Accessed March 4, 2020

12. [12] Office of Minority Health. Diabetes and Hispanic Americans. Department of Health and Human Services. Office of Minority Health. 2019. https://minorityhealth.hhs.gov/omh/browse.aspx?lvl=4\&lvlid=63 Accessed March 4, 2020.

13. [13] Hu J, Wallace DC, McCoy TP, Amirehsani KA. A family-based diabetes intervention for Hispanic adults and their family members. Diabetes Educ. 2014;40(1):48-59.

14. [14] Hu J, Amirehsani K, Wallace DC, Letvak S. Perceptions of barriers in managing diabetes: perspectives of Hispanic immigrant patients and family members. Diabetes Educ. 2013;39(4):494-503.

15. [15] Borson S, Scanlan JM, Chen PJ et al. The Mini-Cog as a screen for dementia: Validation in a population based sample. J Am Geriatr Soc 2003;51:1451-4

16. [16] Rubenstein LZ, Harker JO, Salva A, Guigoz Y, Vellas B. Screening for Undernutrition in Geriatric Practice: Developing the Short-Form Mini Nutritional Assessment (MNA-SF). J. Geront 2001;56A: M36677

17. [17] Green EC, Murphy E. Health Belief Model. The Wiley Blackwell Encyclopedia of Health, Illness, Behavior, and Society. Hoboken, NJ: John Wiley \& Sons, Ltd; 2014.

18. [18] Morley JE, Argiles JM, Evans, et al. Nutritional recommendations for the management of sarcopenia. J Am Med Dir Assoc. 2010;11(6):391-6.

19. [19] Diabetes. Patient educational handouts. Academy of Nutrition and Dietetics (AND). 2019. https://www.dce.org/publications/education-handouts Accessed February 26, 2020.

20. [20] Center for Disease Control and Prevention. Diabetes Eat Well. Series of topics and MyPlate for Diabetes. Center for Disease Control and Prevention, US Department of Health and Human Services https://www.cdc.gov/diabetes/managing/eat-well.html. Accessed February 26, 2020. 
21. [21] National Diabetes Educator Program (NDE). Dietary Guidelines for Americans 2015-2020. National Institutes of Health and the Center for Disease Control and Prevention. https://www.cdc.gov/diabetes/ndep/pdfs/dietary_guidelines_slides.pdfAccessed February 26, 2020.

22. [22] Campbell AJ, Robertson MC, Gardner MM, Norton RN, Buchner DM. Psychotropic medication withdrawal and a home-based exercise program to prevent falls: a randomized, controlled trial. J Am Geriatr Soc. 1999;47(7):850-3.

23. [23] Campbell J, Robertson M. Otago Exercise programme to prevent falls in older adults. A homebased, individually tailored strength and balance retraining programme. Otago Medical School, University of Otago 2003.

24. [24] Campbell AJ, Robertson MC, Gardner MM, Norton RN, Tilyard MW, Buchner DM. Randomised controlled trial of a general practice programme of homebased exercise to prevent falls in elderly women. BMJ. 1997;315(7115):1065-9.

25. [25] Vieira ER, Tappen R, Gropper SS, et al. Changes on walking during street crossing situations and on dorsiflexion strength of older Caribbean Americans after an exercise program: a pilot study. J Aging Phys Act. 2017; 25(4):1-26.

26. [26] Alberti KG, Eckel RH, Grundy SM et al. Harmonizing the metabolic syndrome: a joint interim statement of the International Diabetes Federation Task Force on Epidemiology and Prevention; National Heart, Lung, and Blood Institute; American Heart Association; World Heart Federation; International Atherosclerosis Society; and International Association for the Study of Obesity. Circulation. 2009;120:16405 .

27. [27] International Diabetes Foundation. IDF consensus world definition of the metabolic syndrome. 2006. Brussels, Belgium. $\quad$ https://www.idf.org/e-library/consensus-statements/60-idfconsensus-worldwide-definitionof-themetabolic-syndrome.html Accessed March 2, 2020.

28. [28] Mullen SP, Wójcicki TR, Mailey EL, et al. A profile for predicting attrition from exercise in older adults. Prev Sci. 2013;14(5):489-96.

29. [29] Jancey J, Lee A, Howat P, Clarke A, Wang K, Shilton T. Reducing attrition in physical activity programs for older adults. J Aging Phys Act. 2007;15(2):152-165.

30. [30] Ockene IS, Tellez TL, Rosal MC, et al. Outcomes of a Latino community-based intervention for the prevention of diabetes: the Lawrence Latino Diabetes Prevention Project. Am J Public Health. 2012;102(2):336-42

31. [31] Coleman KJ, Ocana LL, Walker C, et al. Outcomes from a culturally tailored diabetes prevention program in Hispanic families from a low-income school: Horton Hawks Stay Healthy (HHSH). Diabetes Educ. 2010;36(5):784-92

32. [32] Skalko TK, Sauter W, Burgess L, Loy D. Assessing balance and fall efficacy in community-dwelling older adults. Ther Recreation J. 2013;47(4):291-306.

33. [33] Alejandro P, Constantinescu F. A Review of Osteoporosis in the Older Adult. Clin Geriatr Med. 2017;33(1):27-40.

34. [34] Jiang X, Jiang H, Li M, Lu Y, Liu K, Sun X. The Mediating Role of Self-Efficacy in Shaping SelfManagement Behaviors Among Adults With Type 2 Diabetes. Worldviews Evid Based Nurs. 2019;16(2):151-60.

35. [35] Jarbøl DE, Larsen PV, Gyrd-Hansen D, et al. Determinants of preferences for lifestyle changes versus medication and beliefs in ability to maintain lifestyle changes. A population-based survey. Prev Med Rep. 2017;6:66-73.

36. [36] Breland JY, McAndrew LM, Gross RL, Leventhal H, Horowitz CR. Challenges to healthy eating for people with diabetes in a low-income, minority neighborhood. Diabetes Care 2013;36(10):2895-901.

37. [37] Testerman J, Chase D. Influences on diabetes self-management education participation in a lowincome, Spanish-speaking, Latino population. Diabetes Spectrum. 2018;31(1):47-57.

38. [38] Caballero AE. Understanding the Hispanic/Latino patients. Amer J Med. 2011;124:S10-5.

39. [39] Whittemore, R., Vilar-Compte, M., De La Cerda, S. et al. Challenges to diabetes self-management for adults with type 2 diabetes in low-resource settings in Mexico City: a qualitative descriptive study. Int J Equity Health. 2019;18:133. https://doi.org/10.1186/s12939-019-1035-x 